\title{
Effect of cholecystokinin on lower oesophageal sphincter pressure and transient lower oesophageal sphincter relaxations in humans
}

\author{
M Ledeboer, A A M Masclee, M R Batstra, J B M J Jansen, C B H W Lamers
}

\begin{abstract}
The effect of cholecystokinin (CCK) on the lower oesophageal sphincter (LOS) pressure, frequency of transient LOS relaxations, and the number of reflux episodes was investigated in six healthy subjects. LOS pressure was recorded on four separate occasions during continuous intravenous infusion of either saline or CCK-33 in doses of $0 \cdot 25,0 \cdot 5$, or 1.0 Ivy Dog units per kg body weight per hour (IDU. $\mathrm{kg}^{-1} \cdot \mathrm{h}^{-1}$ ) for 90 minutes. Plasma CCK concentrations did not change during saline infusion, but increased significantly from $2 \cdot 5(0 \cdot 3)$ $\mathrm{pmol} / \mathrm{l}$ to steady state levels of $4.0(0.4)$ $\mathrm{pmol} / \mathrm{l}, 6 \cdot 1(0.4) \mathrm{pmol} / \mathrm{h}$, and $9.3(0.9) \mathrm{pmol} / \mathrm{h}$ respectively starting from 30 minutes. LOS pressure did not change significantly during infusion of saline or of CCK-33 at doses of 0.25 or 0.5 IDU. $\mathrm{kg}^{-1} \cdot \mathrm{h}^{-1}$. However, a significant $(p<0 \cdot 05)$ reduction
\end{abstract} in LOS pressure to a minimum level of 12 (4) $\mathrm{mm} \mathrm{Hg}$ at 30 minutes compared with basal level (18 (4) $\mathrm{mm} \mathrm{Hg}$ ) and compared with saline was observed during infusion of CCK-33 at a dose of $1.0 \mathrm{IDU} . \mathrm{kg}^{-1} \cdot \mathrm{h}^{-1}$. In addition, oesophageal motility and $\mathrm{pH}$ were recorded simultaneously in these six subjects on two separate occasions one hour before (fasting) and three hours during administration of a gastric load (dextrose $5 \%$, pH 3) combined with continuous intravenous infusion of saline or CCK-33 at a dose of 1.0 IDU. $\mathrm{kg}^{-1} \cdot \mathrm{h}^{-1}$. Plasma CCK concentrations did not change during the gastric load combined with saline, but increased significantly to a steady state level of $10.8(0.8) \mathrm{pmol} / \mathrm{l}$ during intravenous infusion of CCK. The number of transient LOS relaxations increased significantly in the first hour during administration of the gastric load compared with fasting levels, both during saline infusion (fasting: $1.7(0.6) / \mathrm{h}, 1 \mathrm{st}$ hour: $4.3(1 \cdot 2) / \mathrm{h})$ and during CCK infusion (fasting: $1.7(0.5) / \mathrm{h}$, 1st hour: $3.8(0 \cdot 7) / \mathrm{h})$. In the second and third hours the number of transient LOS relaxations fell to fasting levels in both experiments. No significant differences were observed in the number and type of transient LOS relaxations, mechanism of gastro-oesophageal reflux, or duration of acid exposure between the two experiments. It is concluded that in healthy subjects infusion of CCK-33 in a dose of 1.0 IDU. $\mathrm{kg}^{-1} \cdot \mathrm{h}^{-1}$ significantly reduces LOS pressure but does not affect the frequency of transient LOS relaxations or acid exposure time during a continuous liquid gastric load.

(Gut 1995; 36: 39-44)

Keywords: cholecystokinin, lower oesophageal sphincter pressure.

It has been shown that ingestion of a fatty meal provokes gastro-oesophageal reflux in patients with reflux disease ${ }^{1}$ but the mechanism of this remains to be explained. Since it is well known that ingestion of a fatty meal lowers the basal lower oesophageal sphincter (LOS) pressure, it has been suggested that this is the cause of the reflux..$^{2}$ Reflux induced by an insufficient LOS barrier occurs only at very low sphincter pressures, generally below $6 \mathrm{~mm} \mathrm{Hg} .{ }^{4}$ In most subjects, however, the residual LOS pressure in response to fat ingestion remains above this value. Several recent studies have shown that in both healthy subjects and in patients with reflux disease, postprandial gastro-oesophageal reflux predominantly results from transient relaxations of the LOS rather than from a decrease in LOS pressure. ${ }^{4-8}$ Gastric distension is clearly identified as one of the triggers of these transient LOS relaxations but the role of other factors, such as nutrients or gastrointestinal hormones, is still unknown. ${ }^{9}$

A fatty meal is a potent stimulus of cholecystokinin (CCK) release and CCK may be responsible for the fat induced increase in gastro-oesophageal reflux. ${ }^{231011}$ Results of studies on the effect of CCK on the LOS pressure have been controversial. Infusion of CCK in humans has been reported to reduce the LOS pressure in some studies, but in a recent study by Brazer et al, a reduction in pressure was shown only at supraphysiological doses of CCK. ${ }^{12-16}$

In this study we have investigated the effect of different doses of CCK-33 that reached plasma CCK concentrations in the physiological postprandial range, on the basal LOS pressure (protocol I). In addition we investigated the effect of a high but physiological dose of CCK-33 on the number of transient LOS relaxations and the mechanism of reflux (protocol II). A continuous gastric load was applied in this protocol to reproduce postprandial gastric distension. 


\section{Methods}

SUBJECTS

Six healthy volunteers (two men, four women; mean age 22 years, range 19-24 years) participated in the study. They were studied after an overnight fast and refrained from smoking at least 10 hours before the experiments. None had a history of gastrointestinal disease or surgery and none was taking any medication. Informed consent was obtained from each individual and the protocols had been approved by the ethical committee of the Leiden University Hospital.

MANOMETRIC AND PH RECORDING TECHNIQUE Oesophageal pressure recordings were obtained using a polyvinyl assembly of $5 \mathrm{~mm}$ outer diameter incorporating a $6 \mathrm{~cm}$ long sleeve sensor and seven side holes, one located at the distal margin to monitor intragastric pressure and six at $0,3,6,9,15$, and 24 or $30 \mathrm{~cm}$ respectively from the upper margin of the sleeve sensor (Dent Sleeve, Arndorfer Medical Systems, Greendale, WI, USA). ${ }^{17}$ Oesophageal $\mathrm{pH}$ was monitored with a glass $\mathrm{pH}$ electrode (Ingold LOT 440 continuous glass-reference $\mathrm{pH}$ electrode; Ingold Messtechnik AG, Urdorf, Germany). The manometric assembly and $\mathrm{pH}$ electrode were passed transnasally into the oesophagus and the sleeve sensor was positioned so that it permitted continuous monitoring of the LOS pressure. Simultaneously pressures were recorded from the gastric fundus, LOS (sleeve), oesophageal body (side holes 3, 9, and $15 \mathrm{~cm}$ above the upper margin of the sleeve sensor), and pharynx (24 or $30 \mathrm{~cm}$ above sleeve sensor). The side holes and sleeve sensor were connected to a pressure transducer (Medex, Hilliard, Ohio, USA) and perfused with gas free distilled water by a low compliance pneumohydraulic infusion pump (Arndorfer Medical Supplies, Greendale, WI, USA) at a rate of $0.5 \mathrm{ml} / \mathrm{min}$. The side hole located in the pharynx, used to monitor swallows, was waterfilled but not perfused to avoid excessive swallowing. The $\mathrm{pH}$ electrode was positioned $5 \mathrm{~cm}$ above the upper margin of the LOS. The electrode was calibrated in buffers of pH 4 and 7 before and after each study. The outputs from the pressure transducers and $\mathrm{pH}$ electrode were processed by an eight channel polygraph (Synectics Medical, Stockholm, Sweden) displayed on a monitor and stored on a personal computer system.

\section{STUDY PROTOCOL I}

The subjects were studied on four separate occasions in random order. The experiments began at 9 am after an overnight fast. After positioning and securing of the manometric assembly, two intravenous cannulas were inserted into the antecubital veins of each arm. One cannula was used for blood sampling, the other for CCK infusion. The subjects were studied in the upright position, sitting in a comfortable chair. LOS pressure was recorded continuously for a
30 minute basal period from -30 to 0 minutes and from 0 to 90 minutes during continuous intravenous infusion of either saline or CCK-33 (Ferring, Malmö, Sweden) in doses of $0 \cdot 25$, 0.5 , or 1.0 Ivy Dog units per $\mathrm{kg}$ body weight/hour (IDU. $\mathrm{kg}^{-1} \cdot \mathrm{h}^{-1}$ ) respectively. Blood samples for measurement of plasma CCK concentrations were obtained at time $-30,-15$, and 0 minutes before intravenous infusion, and at time 15,30,60, and 90 minutes during intravenous infusion of CCK or saline.

\section{STUDY PROTOCOL II}

The subjects were studied on two separate occasions and the experiments were performed in random order. The experiments were started at 9 am after an overnight fast. The manometric assembly and $\mathrm{pH}$ electrode were positioned as described above. Two intravenous cannulas - one for blood sampling, the other for CCK infusion - were inserted into the antecubital veins of each arm. Oesophageal motility and $\mathrm{pH}$ were recorded simultaneously for one hour in the fasting state and for three hours during intravenous infusion of saline (control) or CCK-33 in a dose of 1.0 IDU. $\mathrm{kg}^{-1} \cdot \mathrm{h}^{-1}$. At the onset of the three hour infusion period, the subjects ingested $300 \mathrm{ml}$ dextrose $5 \%$ at $\mathrm{pH} 3$, to provoke a postprandial like gastric distension. In presuming a gastric emptying half time for liquids of 20 minutes, a gastric volume of $240-300 \mathrm{ml}$ was maintained throughout the experiment after administration of the $300 \mathrm{ml}$ bolus and continuous administration of dextrose $5 \%$ through the intragastric side hole of the manometric assembly at a rate of $6 \mathrm{ml} / \mathrm{min}$. Blood samples for measurement of plasma CCK concentrations were obtained 60,30 , and 0 minutes before the infusion and at $15,30,60,90,120$, and 180 minutes during continuous intravenous infusion of saline or CCK-33. The subjects were seated upright in a comfortable chair.

\section{ASSAY OF CCK}

Blood samples were collected in tubes containing EDTA and kept on ice during the experiment. Plasma CCK was measured by a sensitive and specific radioimmunoassay using antibody $T_{204} \cdot{ }^{18} 19$ This antibody binds to all carboxy-terminal CCK peptides containing the sulphated tyrosyl region. The detection unit of the assay was $0.5 \mathrm{pmol} / 1$ plasma. The intraassay variation ranged from $4 \cdot 6-11 \cdot 5 \%$ and the interassay variation from $11 \cdot 3-26 \cdot 1 \% .{ }^{19}$

\section{DATA ANALYSIS}

The experiments in study protocols I and II were performed in random order. Each manometric or $\mathrm{pH}$ tracing was coded. Analysis of the tracings was performed in a blinded fashion so that the investigators (MRB and AAMM) who analysed the recordings were not aware whether or not CCK had been infused and of the dose of CCK infused.

The pressure and $\mathrm{pH}$ tracings were analysed visually for basal LOS pressure, the occurrence 
of LOS relaxations and the duration of $\mathrm{pH}<4$. Mean end expiratory LOS pressure was determined at 10 minute intervals, measured for one minute and referenced to end expiratory intragastric pressure defined as zero.

Transient LOS relaxations were defined as an abrupt ( $>1 \mathrm{~mm} \mathrm{Hg} / \mathrm{s}$ ) fall in LOS pressure of more than $5 \mathrm{~mm} \mathrm{Hg}$ to a level $<2 \mathrm{~mm} \mathrm{Hg}$ above intragastric pressure for more than 5 seconds. No swallow signals were to be present 5 seconds before the onset of LOS relaxation or until maximal LOS relaxation had been achieved. The number of transient LOS relaxations were counted at one hour intervals.

Gastro-oesophageal reflux was defined as an abrupt fall in oesophageal $\mathrm{pH}$ below 4 for at least 4 seconds. If oesophageal $\mathrm{pH}$ was already below 4, a drop in $\mathrm{pH}$ of more than one $\mathrm{pH}$ unit for at least 4 seconds was also scored as a reflux episode. In addition, the mechanism for each reflux episode was identified according to the following:

(1) Gastro-oesophageal reflux during a transient LOS relaxation (LOS relaxation meeting earlier mentioned criteria; spontaneous or post swallow relaxation or synchronous contraction in the distal oesophagus).

(2) Reflux during a swallow induced LOS relaxation (primary peristalsis, failed peristalsis, or multiple swallowing).

(3) Free reflux across a defective LOS pressure (less than $2 \mathrm{~mm} \mathrm{Hg}$ above intragastric pressure).

(4) Reflux as a result of a gradual loss of basal LOS pressure (pressure drift) or

(5) Reflux accompanied by an increase in abdominal pressure (stress reflux).

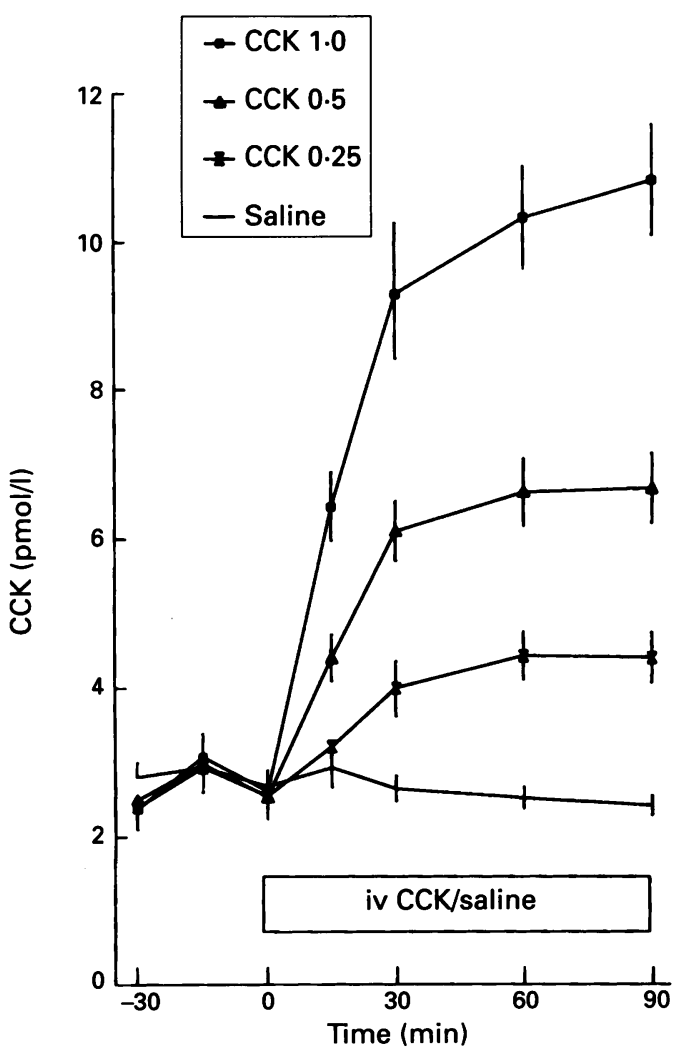

Figure 1: Plasma cholecystokinin (CCK) concentration (pmoll, mean (SEM)) during continuous intravenous infusion of saline or CCK-33 in doses of $0.25,0.5$, and 1.0 Ivy Dog units per kg body weight per hour for 90 minutes.

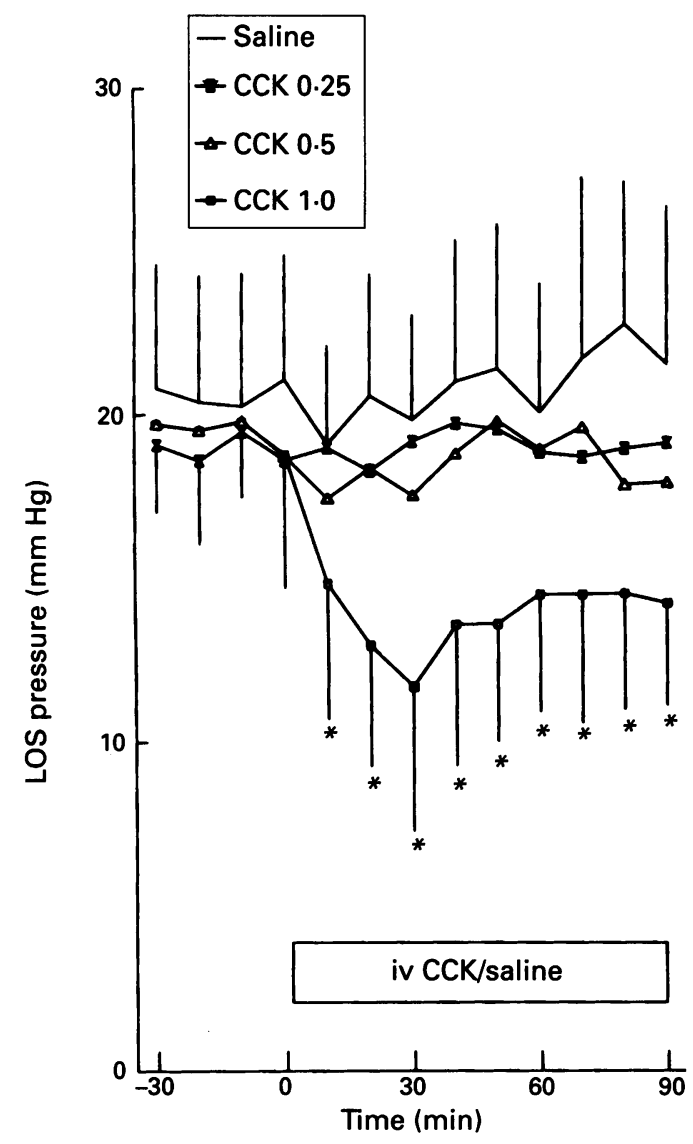

Figure 2: Lower oesophageal sphincter pressure ( $\mathrm{mm} \mathrm{Hg}$, mean (SEM)) during continuous intravenous infusion of saline or cholecystokinin (CCK-33) in doses of 0.25, 0.5, and 1.0 Ivy Dog units per kg body weight per hour for 90 minutes. The asterisks denote significant $(p<0.05)$ differences compared with basal levels and saline infusion.

\section{STATISTICAL ANALYSIS}

Results are expressed as mean (SEM). LOS pressures are expressed in $\mathrm{mm} \mathrm{Hg}$ and plasma CCK concentrations in $\mathrm{pmol} / \mathrm{l}$. Differences in LOS pressures and CCK values between the experiments in protocol I were analysed for statistical significance by a multiple analysis of variance (MANOVA). When this indicated a probability of less than 0.05 for the null hypothesis, Student-Newman-Keuls analyses were performed to determine which values between or within the experiments differed significantly. The significance level was set at $\mathrm{p}<0.05$. The number of transient LOS relaxations and gastro-oesophageal reflux episodes in the experiments of protocol II were compared using paired Student's $t$ tests. The significance level was set at $\mathrm{p}<0.05$.

\section{Results}

\section{STUDY PROTOCOL I}

\section{Plasma CCK concentrations}

Basal plasma CCK concentrations were not significantly different among the four experiments (Fig 1): $2.7(0.2) \mathrm{pmol} / 1$ (saline), 2.5 $(0.3) \mathrm{pmol} / 1$ (CCK 0.25 IDU.kg $\left.{ }^{-1} . \mathrm{h}^{-1}\right), 2.5$ $(0.3) \mathrm{pmol} / 1\left(0.5 \mathrm{IDU} . \mathrm{kg}^{-1} \cdot \mathrm{h}^{-1}\right)$, and $2.6(0.4)$ $\mathrm{pmol} / 1\left(1.0 \mathrm{IDU} \cdot \mathrm{kg}^{-1} \cdot \mathrm{h}^{-1}\right)$. Infusion of $0 \cdot 25$, 0.5 , and 1.0 IDU. $\mathrm{kg}^{-1} \cdot \mathrm{h}^{-1}$ of CCK-33 resulted in significant $(p<0.05)$ increases in 


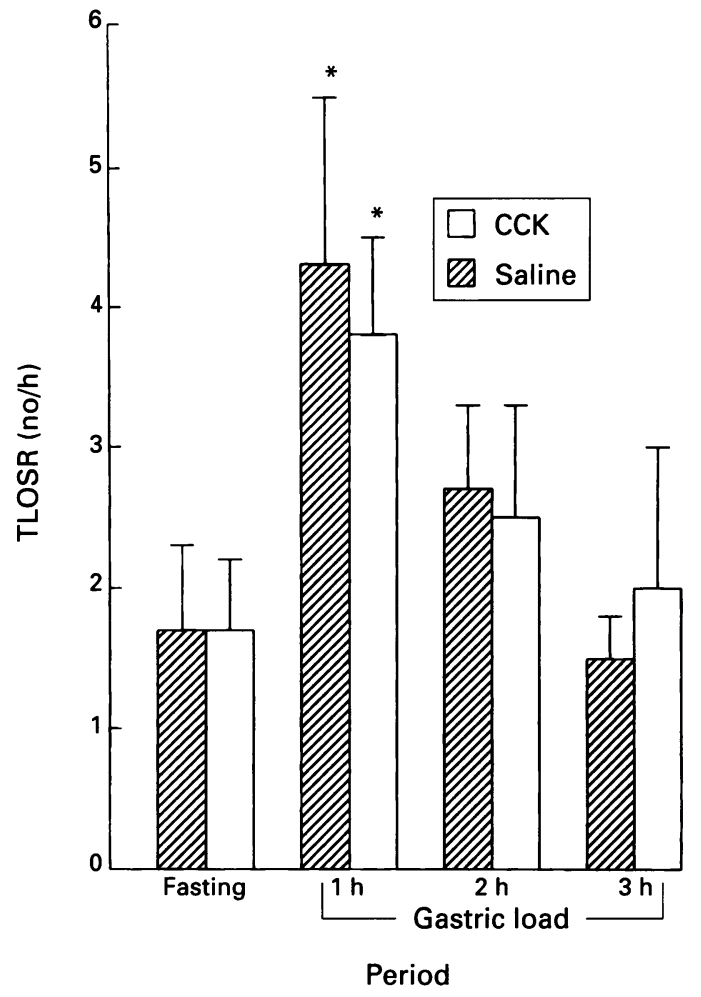

Figure 3: Numbers of transient lower oesophageal sphincter relaxations (TLOSR) per hour (mean (SEM)) one hour before and three hours during administration of a gastric load of dextrose $5 \%$ in combination with either saline or cholecystokinin (CCK-33) intravenously at a dose of 1.0 IDU. $\mathrm{kg}^{-1} . \mathrm{h}^{-1}$. The asterisks denote significant $(p<0.05)$ differences compared with fasting levels.

plasma CCK concentrations compared with basal values and with the control experiment (saline) starting from 15 minutes. During CCK infusion, steady state plasma CCK values of $4.0(0.4) \mathrm{pmol} / \mathrm{l}, 6 \cdot 1(0.4) \mathrm{pmol} / \mathrm{l}$, and $9.3(0.9) \mathrm{pmol} / 1$ were reached at 30 minutes during infusion of $0.25,0.5$, and 1.0 IDU. $\mathrm{kg}^{-1} \cdot \mathrm{h}^{-1}$ respectively. Steady state plasma CCK concentrations were maintained throughout the infusion period.

\section{LOS pressure}

LOS pressures in the basal periods from -30 to 0 minutes were not significantly different between the four experiments (Fig 2). Infusion of saline (basal LOS pressure: 21 (4) $\mathrm{mm} \mathrm{Hg}$ ) did not induce significant changes in LOS pressure. Neither infusion of CCK-33 at a rate of 0.25 or 0.5 IDU. $\mathrm{kg}^{-1} \cdot \mathrm{h}^{-1}$ (basal pressures 18 (2) $\mathrm{mm} \mathrm{Hg}$ and 19 (3) $\mathrm{mm} \mathrm{Hg}$ respectively) induced significant changes in LOS pressure. However, CCK infused at a rate of 1.0 IDU. $\mathrm{kg}^{-1} \cdot \mathrm{h}^{-1}$ significantly $(\mathrm{p}<0.05)$ decreased pressure both compared with basal (LOS pressure 18 (4) $\mathrm{mm} \mathrm{Hg}$ ) and control experiment starting from 10 minutes (15 (4) $\mathrm{mm} \mathrm{Hg}$ ) and continuing throughout the entire experiment, reaching a minimum of 12 (4) $\mathrm{mm}$ $\mathrm{Hg}$ at 30 minutes.

\section{STUDY PROTOCOL II}

Plasma CCK concentrations

Fasting plasma CCK concentrations were not significantly different between the two experiments or compared with the fasting plasma CCK concentrations observed in study protocol I. Infusion of saline did not significantly change plasma CCK values, whereas infusion of 1.0 IDU. $\mathrm{kg}^{-1} \cdot \mathrm{h}^{-1}$ of CCK-33 significantly $(p<0.05)$ increased plasma CCK concentrations starting from 15 minutes and reaching a steady state level of $10.8(0.8)$ $\mathrm{pmol} / \mathrm{l}$ beyond 30 minutes.

\section{Transient LOS relaxations}

The number of transient LOS relaxations per hour during the fasting period were not significantly different between the two experiments (saline: $1.7(0.6) / \mathrm{h}$ and CCK $1.7(0.5) / \mathrm{h}$; Fig $3)$. The total number of transient LOS relaxations in all subjects during the three hour saline infusion period were comparable with the total number during the three hours CCK infusion ( 51 and 50 respectively). A significant $(p<0.05)$ increase in transient LOS relaxations compared with fasting values was observed in the first hour after ingestion of the gastric load followed by both infusion of saline $(4 \cdot 3$ $(1 \cdot 2) / \mathrm{h})$ or CCK $(3.8(0 \cdot 7) / \mathrm{h})$. However, in the second and third hours after starting the gastric load the number of transient LOS relaxations per hour decreased to fasting levels, both in the saline (second hour: $2 \cdot 7(0.6) / \mathrm{h}$, third hour: $1.5(0.3) / \mathrm{h}$ ) and CCK (second hour: 2.5 $(0 \cdot 8) / \mathrm{h}$ and third hour: $2 \cdot 0(1 \cdot 0) / \mathrm{h})$ experiments. Significant differences between the two experiments were not observed. A possible, small effect of CCK on transient LOS relaxation frequency could, however, have been masked by administration of the gastric load. We therefore analysed the manometric tracings of study protocol I for the occurrence of transient LOS relaxations during saline infusion (control) and infusion of CCK-33 at 1.0 IDU. $\mathrm{kg}^{-1} \cdot \mathrm{h}^{-1}$ when no gastric load was given. The number of transient LOS relaxations per hour during CCK infusion $(1.4(0.4) / \mathrm{h})$ was not significantly different from that during saline infusion $(1.5(0 \cdot 6) / \mathrm{h})$.

\section{MECHANISMS OF GASTRO-OESOPHAGEAL} REFLUX

The total numbers of gastro-oesophageal reflux episodes in all subjects were 14 during saline infusion and 18 during CCK infusion (Table I). The predominant mechanism of reflux in both experiments was reflux during transient LOS relaxations: 12 (86\%) episodes occurred during saline infusion and $16(89 \%)$

TABLE I Mechanism of gastro-oesophageal reflux during three hours of installation of a gastric load combined with intravenous infusion of either saline (control) or $C C K-33$ at a rate of $1.0 \mathrm{IDU} . \mathrm{kg}^{-1} . \mathrm{h}^{-1}$

\begin{tabular}{lll}
\hline Mechanism & $\begin{array}{l}\text { Saline infusion } \\
\text { No (\%) }\end{array}$ & $\begin{array}{l}\text { CCK infusion } \\
\text { No (\%) }\end{array}$ \\
\hline Transient LOS relaxation & $12(86)$ & $16(88)$ \\
Swallow induced & $1(7)$ & $1(6)$ \\
Pressure drift & $0(0)$ & $1(6)$ \\
Abdominal strain & $1(7)$ & $0(0)$ \\
Absent LOS pressure & $0(0)$ & $0(0)$ \\
Total reflux episodes & $14(100)$ & $18(100)$ \\
\hline
\end{tabular}


TABLE II Duration of acid exposure (percentage of time $\mathrm{pH}<4$ ) (mean and range) before (fasting) and during three hours of installation of a gastric load combined with intravenous infusion of either saline (control) or CCK-33 at a rate of $1 \cdot 0 \mathrm{IDU} . \mathrm{kg}^{-1} \cdot \mathrm{h}^{-1}$

\begin{tabular}{lll}
\hline \multirow{2}{*}{ Time } & \multicolumn{2}{l}{ Duration of acid exposure (\%) } \\
\cline { 2 - 3 } & Saline & $C C K$ \\
\hline Fasting & $0.05(0-0.31)$ & $0(0)$ \\
Gastric load & $0.14(0-0.68)$ & $0.10(0-0.27)$ \\
\hline
\end{tabular}

during CCK infusion. One (7\%) reflux episode during saline infusion and one (5\%) episode during CCK infusion occurred during a swallow induced LOS relaxation. In the CCK infusion experiment, one $(7 \%)$ other reflux episode was caused by a pressure drift of the LOS, and in the saline experiment one was caused by abdominal straining. No reflux episodes were observed caused by a very low or absent LOS pressure. There were no significant differences observed in mechanisms of reflux between the two experiments.

\section{DURATION OF ACID EXPOSURE}

The duration of acid exposure was low in this group of healthy subjects. The preprandial $\mathrm{pH}$ was $<4$ during $0.05 \%(0-0.31 \%)$ before saline infusion and $0 \%$ before CCK infusion (Table II, not significant). No significant differences were observed in percentage of time that the oesophageal $\mathrm{pH}$ was $<4$ during saline infusion $(0 \cdot 14 \%$, range $0-0.68 \%)$ or during CCK infusion $(0 \cdot 10 \%$, range $0-0 \cdot 27 \%)$. The increase in acid exposure time during administration of the gastric load with either saline or intravenous CCK was not significant compared with fasting levels.

\section{Discussion}

We have shown that CCK-33 infusion in a dose of 1.0 IDU. $\mathrm{kg}^{-1} \cdot \mathrm{h}^{-1}$ significantly reduces LOS pressure. In contrast, infusion of CCK33 in doses of 0.25 or 0.5 IDU. $\mathrm{kg}^{-1} \cdot \mathrm{h}^{-1}$ did not affect LOS pressure. The plasma CCK concentrations reached at these lower infusion rates $\left(0.25\right.$ and 0.5 IDU. $\left.\mathrm{kg}^{-1} . \mathrm{h}^{-1}\right)$ are well within the physiological postprandial range of plasma CCK. During infusion of 0.25 and 0.5 IDU. $\mathrm{kg}^{-1} \cdot \mathrm{h}^{-1}$, plasma CCK concentrations of 4.0 and $6 \cdot 1 \mathrm{pmol} / 1$ respectively were reached at 30 minutes. These values are comparable with those observed after ingestion of a low and medium fat mixed meal. ${ }^{1011}$ Infusion of CCK-33 at a rate of 1.0 IDU. $\mathrm{kg}^{-1} \cdot \mathrm{h}^{-1}$ resulted in a steady state plasma CCK concentration of $9.3 \mathrm{pmol} / 1$ at 30 minutes, eventually reaching a level of $10.9 \mathrm{pmol} / \mathrm{l}$. Even such plasma CCK levels are within the physiological postprandial range and have been observed after ingestion of a high fat meal. ${ }^{20}$

We have therefore shown that CCK affects LOS pressure at high but physiological plasma levels. These findings partly agree with the observations of Brazer et al. ${ }^{16}$ These investigators report, as confirmed in our study, that physiological plasma concentrations of CCK-8 up to $7 \cdot 4 \mathrm{pmol} / \mathrm{l}$ do not affect LOS pressure.
However, supraphysiological levels of CCK-8 (beyond a plasma CCK level of $12 \cdot 1 \mathrm{pmol} / \mathrm{l}$ ) significantly reduced LOS pressure, suggesting that only supraphysiological doses of CCK affects LOS pressure. Unfortunately, in the study of Brazer et al the effect of CCK on LOS pressure during plasma CCK concentrations in the high physiological range (between 7.5 and $12 \mathrm{pmol} / \mathrm{l}$ ) was not investigated. Furthermore, the dose-response effect of CCK-8 on LOS pressure was investigated using increasing CCK doses in a stepwise fashion on the same day, whereas in our study each dose of CCK was infused on a different day. In addition, in the study of Brazer et al every CCK dose was infused only for a 20 minute period, which in our opinion is too short to reach steady state plasma CCK values. In our study we investigated the effect of each dose of CCK on separate days over a 90 minute infusion period, reaching steady state plasma CCK levels for each dose.

The role of this CCK induced LOS pressure reduction in the occurrence of gastrooesophageal reflux after a fatty meal in healthy subjects is probably of minor importance. During infusion of 1.0 IDU. $\mathrm{kg}^{-1} \cdot \mathrm{h}^{-1}$, LOS pressure fell from 18 (4) $\mathrm{mm} \mathrm{Hg}$ to a minimum of 12 (4) $\mathrm{mm} \mathrm{Hg}$. As pointed out previously, reflux through a low LOS barrier occurs only at very low pressure, generally below $6 \mathrm{~mm}$ $\mathrm{Hg} .{ }^{4}$ Even at the high plasma CCK concentrations reached in the postprandial period, such a reduction will not occur, at least in healthy subjects with a normal basal LOS pressure. Furthermore, several recent studies have shown that postprandial gastro-oesophageal reflux results predominantly from transient LOS relaxation. ${ }^{4-8}$

To investigate further the role of CCK in fat induced postprandial reflux, we studied the effect of CCK-33 in a dose of 1.0 IDU. $\mathrm{kg}^{-1} \cdot \mathrm{h}^{-1}$ on the number of transient LOS relaxations and the mechanism of reflux. This dose of CCK-33 was chosen after completion of protocol I, as it proved to be the only dose that significantly affected LOS pressure. One of the well known postprandial triggers of transient LOS relaxations is gastric distension. ${ }^{9}$ In addition, reflux of gastric contents probably becomes more apparent when the stomach contains a certain load or volume. We therefore studied the effect of CCK during instillation of a gastric load of dextrose $5 \%$ at $\mathrm{pH}$ 3. This significantly increased the number of transient LOS relaxations, both during saline and CCK infusion, when compared with fasting levels. This finding of a three- to fourfold increase during the first hour after the intragastric load agrees with previous studies on the effect of gastric distension on transient sphincter relaxations using a gastric balloon or meals in healthy subjects. ${ }^{91-23}$ Infusion of CCK-33 did not affect the number of transient LOS relaxations beyond the effect of the gastric load. Compared with saline infusion, no differences in the total number of transient LOS relaxations were observed during CCK infusion (51. during saline, 50 during CCK infusion), nor were differences observed in the 
frequency per hour. The total number of reflux episodes was slightly, but not significantly, increased during CCK infusion (18 versus 14) and no differences were observed in the mechanisms of gastro-oesophageal reflux (Table I) or the duration of acid exposure (Table II). Analysis of the mechanisms of gastro-oesophageal reflux showed that reflux predominantly occurred during transient LOS relaxations in both groups.

To our knowledge, this study is the first to report on the effect of CCK infusion on the frequency of transient LOS relaxations and the mechanism of gastro-oesophageal reflux. Our results do not indicate that CCK provokes either, and do not therefore support an important role for CCK in fat induced gastrooesophageal reflux, at least in healthy subjects. In a recent study, it has even been questioned whether fat increases reflux in healthy subjects. ${ }^{24}$ In our healthy subjects the frequency of transient LOS relaxations and the number of reflux episodes were very low. Our results do not, however, exclude an important role for CCK in LOS pressure reduction, occurrence of transient LOS relaxation, and acid reflux in patients with reflux oesophagitis. Further studies in patients with symptomatic gastrooesophageal reflux or reflux oesophagitis are therefore needed.

In conclusion, we have shown that the infusion of CCK in high but physiological doses significantly reduces LOS pressure but that its relevance in fat induced gastrooesophageal reflux in healthy subjects is probably small. In addition, we have shown that the infusion of CCK does not increase the frequency of transient LOS relaxations or the number of reflux episodes in healthy subjects during a continuous liquid gastric load.

This study was supported by a grant from the Nutricia Research Foundation, Nutricia Nederland BV.

1 Becker DJ, Sinclair J, Castell DO, Wu WC. A comparison of high and low fat meals on postprandial esophageal acid of high and low fat meals on postprandial esoph

2 Nebel OT, Castell DO. Lower esophageal sphincter pressure changes after food ingestion. Gastroenterology 1972; 63: 778-83.

3 Babka JC, Castell DO. On the genesis of heartburn, the effects of specific foods on the lower esophageal sphincter. Am $\mathcal{F}$ Dig Dis 1973; 18: 391-6.

4 Dent J, Dodds WJ, Friedmann RH, Sekiguchi T, Hogan WJ, Arndorfer RC, Petrie DJ. Mechanism of gastro- esophageal reflux in recumbent asymptomatic human subjects. $f$ Clin Invest 1980; 65: 256-67.

5 Dodds WJ, Dent J, Hogan WJ, Helm JF, Hauser R, Patel GK, Egide MS. Mechanism of gastroesophageal reflux in patients with reflux esophagitis. $N$ Engl f Med 1982; 307: 1547-52.

6 Mittal RK, McCallum RW. Characteristics of transient lower esophageal sphincter relaxations in humans. $A m \mathcal{F}$ Physiol 1987; 252: G636-41.

7 Dent J, Holloway RH, Toouli J, Dodds WJ. Mechanisms of lower oesophageal sphincter incompetence in patients with symptomatic gastro-oesophageal reflux. Gut 1988; 29: $1020-8$.

8 Mittal RK, McCallum RW. Characteristics and frequency of transient relaxations of the lower esophageal sphincter in patients with reflux esophagitis. Gastroenterology 1988; 95: $593-9$.

9 Holloway RH, Hongo M, Berger K, McCallum RW. Gastric distention: a mechanism for postprandial gastroesophageal reflux. Gastroenterology 1985; 89: 779-84.

10 Hopman WPM, Jansen JBMJ, Lamers CBHW. Comparative study of the effects of equal amounts of fat, protein and starch on plasma cholecystokinin in man. Scand 7 Gastroenterol 1985; 20: 843-7.

11 Liddle RA, Goldfine ID, Rosen MS, Taplitz RA, Williams JA. Cholecystokinin bioactivity in human plasma: Molecular forms, responses to feeding, and relation to gallbladder contraction. $f$ Clin Invest 1985; 75: to gallbladd $1144-52$.

12 Resin H, Stern DH, Sturdevant RAL, Isenberg JI. Effect of the C-terminal octapeptide of cholecystokinin on lower esophageal sphincter pressure in man. Gastroenterology 1973; 64: 946-9.

13 Fisher RS, Dimarino AJ, Cohen S. Mechanism of cholecystokinin inhibition of lower esophageal sphincter pressure. Am f Physiol 1975; 228: 1469-73.

14 Sturdevant RAL, Kun T. Interaction of pentagastrin and the octapeptide of cholecystokinin on the human lower esophageal sphincter. Gut 1974; 15: 700-2.

15 Katschinski M, Koppelberg T, Wank U, Adler G, Rovati L, Arnold R. CCK plays a role as a physiological regulator of human esophageal motility. Gastroenterology 1990; 98: A365.

16 Brazer SR, Borislow DS, Liddle RA. Cholecystokinin is not a major hormonal regulator of lower esophageal sphincter pressure. Gastroenterology 1990; 99: 641-5.

17 Dent J. A new technique for continuous sphincter pressure measurement. Gastroenterology 1976; 71: 263-7.

18 Jansen JBMJ, Lamers CBHW. Radioimmune assay of cholecystokinin in human tissue and plasma. Clin Chim Acta 1983; 131: 305-16.

19 Jansen JBMJ, Lamers CBHW. Molecular forms of cholecystokinin in plasma from normal and gastrectomized tokinin in plasma from normal and gastrectom

20 Fried M, Mayer EA, Jansen JBMJ, Lamers CBHW, Taylor IL, Bloom SR, Meyer JH. Temporal relationships of cholecystokinin release, pancreatobiliary secretion and gastric emptying of a mixed meal. Gastroenterology 1988; 95: $1344-50$.

21 Penagini R, Bartesaghi B, Conte D, Bianchi PA. Rate of transient lower oesophageal sphincter relaxations of healthy humans after eating a mixed nutrient meal: time course and comparison with fasting. European fournal of Gastroenterology and Hepatology 1992; 4: 35-8.

22 Freidin N, Ren J, Sluss J, McCallum RW. The effect of a large meal and graded intragastric distention on transient LES relaxations (TLESR) frequency in normals. LES relaxations (TLESR) freq
Gastroenterology 1988; 95: A866.

23 Freidin N, Ren J, Sluss J, McCallum RW. The effect of a large meal on the frequency and quality of transient LES relaxations (TLESR). Gastrointestinal Motility 1989; 1: A62.

24 Ireland A, Lyrenas E, Tippett M, Dent J, Holloway RH. Provocation of transient lower esophageal sphincter relaxations and gastroesophageal reflux by intraduodenal fat. Gastroenterology 1990; 98: A361. 